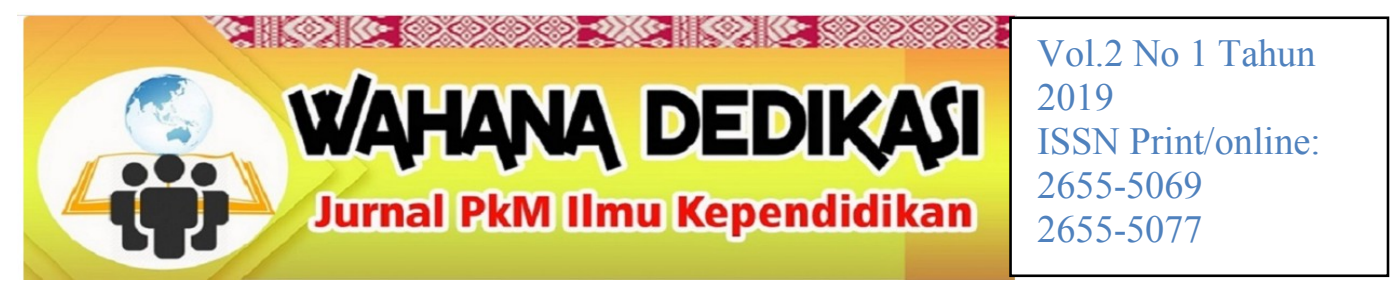

\title{
PELATIHAN PENGGUNAAN TEKNOLOGI \\ INFORMASI KEPADA GURU BIMBINGAN \\ DAN KONSELING
}

\author{
Triyono $^{1}$, Rahmi Dwi Febriani ${ }^{2}$, Hafiz Hidayat ${ }^{3}$, Besti Nora Dwi Putri ${ }^{4}$, \\ Program Studi Bimbingan dan Konseling STKIP PGRI Sumatera Barat ${ }^{1,3,4}$ \\ Jurusan Bimbingan dan Konseling, Universitas Negeri Padang ${ }^{2}$ \\ Email : triono@stkip-pgri-sumbar.ac.id ${ }^{1}$, amidwifebriani@gmail.com $^{2}$, \\ hidayathafiz90@gmail.com ${ }^{3}, \underline{\text { besti@stkip-pgri-sumbar.ac.id }}{ }^{4}$.
}

\begin{abstract}
Abstrak
Pelatihan ini bertujuan agar para Guru Bimbingan dan Konseling dapat menggunakan Teknologi Informasi untuk pelayanan bimbingan dan konseling di sekolah. Pelatihan ini dilaksanakan pada acara seminar nasional dan workshop profesi bimbingan dan konseling dengan jumlah peserta sebanyak 20 orang setiap sesi. Kegiatan ini merupakan pelatihan singkat yang dilaksanakan sebanyak satu kali pertemuan tatap muka. Metode yang digunakan dalam kegiatan ini yaitu ceramah, tanya jawab, diskusi dan praktik yang pandu secara langsung oleh tim Pengabdian kepada Masayarakat (PkM). Hasil yang diperoleh adalah bahwa para guru sangat antusias, serius dan dapat mempraktikan secara lansung tentang penggunaan teknologi informasi untuk pelayanan bimbingan dan konseling.
\end{abstract}

Kata Kunci: Teknologi, Informasi, Bimbingan dan Konseling.

\begin{abstract}
This training aims to let teachers guidance and Counselling can use information technology to the service of guidance and counselling in schools. This training is carried out at the national ceonverence and workshop the guidance and counseling professions with the number of participants by as much as 20 people. This activity is a short training carried out by as much as one time face-toface meetings. The method used in this activity is lecture, question and answer, discussion and practice that is guided directly by the Community Service team. The result is that the teachers are very enthusiastic, serious and can practice in directly on the use of information technology for the Ministry of guidance and counselin.
\end{abstract}

Keyword: technology, information, guidance and counselling

Artikel disetujui tanggal:28-04-2019

Corresponden Author: Triono e-mail: triono@stkip-pgri-sumbar.ac.id

DOI: http://dx.doi.org/10.31851/dedikasi.v1i2.2829doi 
Triono, Rahmi dwi Febriani, Hafiz Hidayat, Besti Nora dwi Putri (2019)

Pelatihan Penggunaan Teknologi Informasi Kepada Guru Bimbingan Konseling

\section{WAHANA DEDIKASI}

\section{Pendahuluan}

Berbagai Perkembangan dan kemajuan teknologi informasi di era milenial akan berdampak pada berbagai bidang (Fatmawati, 2010; Jamaluddin, 2012; Kholis, 2000) termasuk dalam bidang pendidikan (Triyono \& Febriani, 2018). Kemajuan teknologi informasi akan bermanfaat positif (Nurillah \& Muid, 2014) untuk kemudahan dalam bidang pendidikan terutama sebagai salah satu sumber pengetahuan dan referensi bagi guru Bimbingan dan Konseling di sekolah (Supriatna \& Budiman, 2009). Salah satu manfaat kemajuan teknologi informasi di bidang pendidikan yaitu telah memungkinkan terciptanya lingkungan belajar yang berhubungan dengan jaringan (Supriyanto \& Muhsin, 2008) yang menempatkan Guru Bimbingan dan Konseling di tengah-tengah proses pemberian pelayanan. Adanya teknologi memungkinkan Guru Bimbingan dan Konseling akan mengakses berbagai aplikasi untuk memenuhi sumber pelayanan (Sumarwiyah \& Zamroni, 2017; Triyanto, 2010). Dengan adanya teknologi informasi dan komunikasi dapat memudahkan Guru Bimbingan dan Konseling dalam memberikan pelayanan (Ifdil \& Ardi, 2013; Kwartolo, 2010) dari mana saja, kapan saja, dan dimana saja.

Di era globalisasi yang semakin meningkat ini, kita mau tidak mau harus mengikuti perkembangan teknologi informasi yang semakin berkembang pesat (Riwayadi, 2013). Disamping itu juga kita harus mememiliki sasaran yang hendak dicapai dari upaya pengembangan teknologi informasi. Pada era milenial ini seharusnya kebutuhan akses oleh Guru Bimbingan dan Konseling terhadap teknologi informasi sangat dibutuhkan (Setyoningsih, 2018; Sumarwiyah \& Zamroni, 2017). Salah satu bentuknya penggunaan aplikasi yang mendukung untuk pelayanan bimbingan dan konseling serta sumber digital lainnya. Penggunaan teknologi informasi yang optimal menjadikan Guru Bimbingan dan Konseling lebih mudah dalam memberikan pelayanan bimbingan dan konseling kepada siswa di sekolah. Sejalan dengan proses pembelajaran yang dilakukkan pemerintah dalam kurikulum 2013 bahwasanya Guru Bimbingan dan Konseling harus aktif dalam berbagai bidang pelayanan menemukan bahan pembelajaran secara mendiri, bukan lagi guru yang memberikan materi. Namun Guru Bimbingan dan Konseling hanya sebagai fasilitator dalam proses pemberian layanan, oleh karena itu Guru Bimbingan dan Konseling harus mampu dan mau memanfaatkan tekonolgi informasi secara mandiri dan optimal dalam proses pemberian pelayanan kepada siswa.

Namun kondisi penggunaan teknologi oleh Guru Bimbingan dan Konseling saat ini masih belum berjalan optimal (Kamaluddin, 2011)sesuai dengan yang diharapkan. Hal ini terungkap bahwa masih banyaknya Guru Bimbingan dan Konseling yang memanfaatkan smart phonenya untuk kegiatan yang kurang mendukung dengan tugasnya. Kondisi inilah yang menjadikan 
Triono, Rahmi dwi Febriani, Hafiz Hidayat, Besti Nora dwi Putri (2019)

Pelatihan Penggunaan Teknologi Informasi Kepada Guru Bimbingan Konseling

\section{WAHANA DEDIKASI}

keprihatinan tim pengabdian untuk melaksanakan pengabdian kepada masyarakat. Permaslahan yang diangkat oleh pengabdi adalah (1) apakah pengertian teknologi informasi dan komunikasi; (2) seberapa penting TI dalam proses pemberian pelayanan oleh Guru Bimbingan dan Konseling; (3) apa saja langkah-langkah yang diterapkan dalam mengembangkan TI serta penggunaannya; (4) apakah manfaat teknologi informasi untuk pelayanan bimbingan dan konseling; (5) apa saja permasalahan yang timbul akibat adanya teknologi informasi. Tujuan pengabdian kepada masyarakat ini yaitu: 1) Guru Bimbingan dan Konseling mendapat pemahaman dan pengetahuan tentang pentingnya penggunaan teknologi informasi dalam proses pemberian pelayanan, 2) Guru Bimbingan dan Konseling mampu dan mau memanfatkan teknologi informasi untuk pemberian pelayanan, 3) mengenalkan dan mempraktikan aplikasi teknologi informasi, situs yang bisa diakses digunakan oleh Guru Bimbingan dan Konseling dalam pemberian pelayanan kepada siswa di sekolah.

\section{BAHAN DAN METODE}

Kegiatan pengabdian kepada masyarakat ini dilaksanakan pada hari Sabtu, 5 Mei 2018 di Seminar Nasional dan Workshop Profesi Bimbingan dan Konseling di STKIP PGRI Sumatera Barat. Pelaksanaan kegiatan pengabdian ini menggunakan metode ceramah, tanya jawab, diskusi dan praktik (Anitah, 2014; Sugiyanto, 2009) dalam penggunaan Aplikasi
Teknologi Informasi untuk pelayanan bimbingan dan konseling. Metode ceramah dilaksanakan pada awal kegiatan pengabdian yang mana pemateri menjelaskan bahan-bahan yang relevan dengan pelatihan berkaitan(Anitah, 2014; Sugiyanto, 2009) dengan materi-materi yang perlu diketahui oleh peserta pengabdian. Metode tanya jawab dikalukan setelah pemateri memberikan ceramah (Pasaribu, 2005) kepada Guru Bimbingan dan

Konseling, hal ini dilakukan oleh pemateri sehingga Guru Bimbingan dan Konseling yang masih ragu atau bingung dengan materi disampaikan bisa bertanya secara langsung kepada pemateri. Sementara metode diskusi digunakan dalam rangka untuk memberikan kesempatan (Juniati, 2017) kepada Guru Bimbingan dan Konseling untuk mengungkapkan pengalaman, pendapat, dan usaha yang selama ini sudah dilakukkan yang terkait dengan materi pengabdian, sehingga permasalahan yang dialami atau penjadi penghambat dapat terselesaikan atau terentaskan melalui pengabdian yang dilakukan. Selanjutnya metode praktik dilakukkan untuk memantapkan pemahaman dan penguasaan keterampilan (Ifdil et al., 2017) Guru Bimbingan dan Konseling dalam menggunakan teknologi informasi untuk pelayanan bimbingan dan konseling. Kegiatan pengabdian ini dilaksanakan sebanyak 1 (satu) kali tatap muka dengan rincian sebagai berikut.

Tabel 1 Waktu Pelaksanaan No Waktu Penyaji Kegiatan 
Triono, Rahmi dwi Febriani, Hafiz Hidayat, Besti Nora dwi Putri (2019)

Pelatihan Penggunaan Teknologi Informasi Kepada Guru Bimbingan Konseling

\section{WAHANA DEDIKASI}

1.13.00-14.45 Triyono, M.Pd

Ceramah materi tentang pentingnya penggunaan teknologi bagi Guru Bimbingan dan Konseling

2. 14.45-15.10 Triyono,M.Pd

Tanya Jawab terkait dengan materi yang disampaikan.

3. 15.10-15.45 Yasrial

handra, M.Pd

Diskusi mengungkapkan pengalaman, pendapat, dan usaha yang selama ini sudah dilakukkan yang terkait dengan materi pengabdian

\section{15.45-17.30 Semua TIM PKM}

Praktik memantapkan pemahaman dan penguasaan keterampilan Guru Bimbingan dan Konseling dalam menggunakan teknologi informasi untuk pelayanan bimbingan dan konseling.

\section{HASIL DAN PEMBAHASAN}

Berdasarkan hasil evaluasi kegiatan yang dilakukan dapat dikatan bahwa kegiatan pengabdian menerima materi yang disampaiakan, partisipasi dalam proses tanya jawab, diskusi dan semangat peserta mengikuti praktik. Guru Bimbingan dan konseling sudah bisa mempraktikan penggunaan teknologi informasi untuk pelayanan bimbingan dan konseling.

Kemudian Guru Bimbingan dan Konseling peserta pengabdian meminta nomor hand phone pemateri agar bisa berdikusi lebih lanjut di luar sesi pengabdian. Berdasarkan hasil tersebut kami yakin bahwa kegiatan ini merupakan sebuah trobosan yang bagus untuk meningkatkan pengetahuan, pemahaman, serta keterampilan para
Guru Bimbingan dan Konseling dalam penggunaan teknologi informasi untuk proses pelayanan Bimbingan dan Konseling.

Perkembangan teknologi informasi yang semakin maju memberikan tantangan bagi Guru Bimbingan dan Konseling untuk ikut memanfaatkannya (Fidiyaningrum, 2006). Penggunaan teknologi bagi Guru Bimbingan dan Konseling dimaksudkan untuk membantu Guru Bimbingan dan Konseling dalam memberikan pelayanan bimbingan dan konseling kepada siswa secara optimal, baik itu dalam pemberian layanan secara tatap muka maupun secara mandiri. Dalam kurikulum 2013 Guru Bimbingan dan Konseling benar-benar dituntut untuk aktif dan memiliki wawasan, pengetahuan,dan keterampilan.

Karena hal tersebut sangat penting untuk membentuk karakter siswa di sekolah. Oleh karena itu ini sekolahbeijhgsil harus menyediakan sarana dan prasarana teknologi informasi yang dibutuhkan (Sudarsana, 2018; Supriyanto \& Muhsin, 2008) oleh Guru Bimbingan dan Konseling untuk memberikan pelayanan bimbingan dan konseling. Sarana dan prasarana yang dibutuhkan Guru Bimbingan dan Konseling diantaranya: 1) Jaringan internet; 2) Anjungan informasi; 3) Labor teknologi informasi yang bisa diakses oleh Guru Bimbingan dan Konseling setiap saat.

Akan tetapi kenyataan selama ini menunjukkan bahwa, sebagian besar Guru Bimbingan dan Konseling belum memanfaatkan teknologi informasi secara optimal (Anni, 2012). Hal ini terungkap bahwa 
Triono, Rahmi dwi Febriani, Hafiz Hidayat, Besti Nora dwi Putri (2019)

Pelatihan Penggunaan Teknologi Informasi Kepada Guru Bimbingan Konseling

\section{WAHANA DEDIKASI}

masih banyaknya Guru Bimbingan dan Konseling yang menggunakan smart phone untuk kegiatan yang tidak berkaitan dengan pelayanan, pemahaman dan keterampilan yang kurang mengetahui tentang teknologi informasi. Kondisi ini bisa di atasi dan ditingkatkan dengan kerjasama yang baik antara perguruan tinggi dengan guru bimbingan dan konseling dalam rangka peningkatan keterampilan Guru Bimbingan dan Konseling dengan cara memberikan pelatihan dan penyuluhan kepada Guru Bimbingan dan Konseling tentang penggunaan teknologi informasi untuk pelayanan bimbingan dan konseling kepada siswa.

Setelah mengikuti kegiatan pengabdian tentang pelatihan mencari materi pembelajaran dengan menggunakan teknologi informasi. Guru Bimbingan dan Konseling peserta pelatihan telah mendapatkan wawasan, pengetahuan, keterampilan penggunaan teknologi untuk pelayanan bimbingan dan konseling di sekolah. Selanjutnya pemateri juga memberikan trobosan baru kepada Guru Bimbingan dan Konseling yang selama ini belum optimal memanfaatkan teknologi informasi. Harapan dari Guru Bimbingan dan Konseling dan guru agar kegiatan pengabdian yang dilaksanakan bisa dilakukan secara rutin.

\section{KESIMPULAN}

Penggunakan teknologi
informasi dapat menambah wawasan, pengetahuan, pemahaman, dan keterampilan bagi Guru Bimbingan dan Konseling dalam proses pemberian pelayanan. Penggunaan media teknologi informasi bagi Guru Bimbingan dan Konseling memberikan terobosan baru (Jawandi, Mardiyati, \& Hardjajani, 2013) yang sebelumnya Guru Bimbingan dan Konseling hanya berpatokan pada tatap muka tetapi lebih dari itu guru Bimbingan dan Konseling bisa memanfatkan teknologi informasi dalam pemberian layanan yang lebih luas (Pranoto, Wibowo, \& Atieka, 2017). Kondisi ini akan berjalan dengan baik jika ada kerjasama dari semua kalangan baik itu guru bimbingan dan konseling, kepala sekolah dan prktisi pendidikan lainnya.

Diharapkan kepada para Guru Bimbingan dan Konseling bisa meningkatkan dalam penggunaan dan pemanfaatan teknologi informasi untuk pelayanan Bimbingan dan Konseling. Selanjutnya saya ucapkan terimaksih kepada Guru Bimbingan dan Konseling, Guru, Kepla Sekolah, UP3M STKIP PGRI Sumatera Barat, TIM pelaksana Pengabdian, dan semua pihak yang sudah terlibat dalam pelaksanaan pengabdian kepada masyarakat sehingga kegiatan ini berhasil.

Selanjutnya kepada jurnal penerbit yang sudah memberikan kesempatan untuk mempublikasikan hasil PKM yang sudah dilaksanakan.

\section{DAFTAR PUSTAKA}

Anitah, W. (2014). Strategi Pembelajaran Biologi. repository.ut.

Anni, C. T. (2012). Need Assesment Model Penyusunan Program Bimbingan dan Konseling Bidang Bimbingan Belajar 


\section{VAHANA DEDIKASI}

Berbantuan Sistem Informasi Manajemen Di SMA Negeri Kota Semarang. Educational Management, 1(1).

Fatmawati, E. (2010). Pergeseran Paradigma perpustakaan generasi millenial. Visi Pustaka, 12(2), 7-12.

Fidiyaningrum, A. (2006). Upaya mengembangkan empati mahasiswa dengan memanfaatkan media bimbingan (penelitian pada mahasiswa angkatan 2005 Jurusan Bimbingan dan Konseling Fakultas Ilmu Pendidikan Universitas Negeri Semarang tahun akademik 2005/2006). Universitas Negeri Semarang.

Ifdil, I., \& Ardi, Z. (2013). Konseling Online Sebagai Salah Satu Bentuk Pelayanan E-konseling. Jurnal Konseling Dan Pendidikan, 1(1), 15-22.

Ifdil, I., Ilyas, A., Churnia, E., Erwinda, L., Zola, N., Fadli, R. P., ... Refnadi, R. (2017). Pengolahan Alat Ungkap Masalah (AUM) dengan Menggunakan Komputer Bagi Konselor. Jurnal Aplikasi IPTEK Indonesia, 1(1), 17-24.

Jamaluddin, M. (2012). Metamorfosis Pesantren Di Era Globalisasi. KARSA: Journal of Social and Islamic Culture, 20(1), 127-139.

Jawandi, A., Mardiyati, S., \& Hardjajani, T. (2013). Permainan Smart Monopoly untuk Meningkatkan Kreativitas Anak. Consilium:
Jurnal Program Studi Bimbingan Dan Konseling, 1(2), 1-6.

Juniati, E. (2017). Peningkatkan hasil belajar matematika melalui metode drill dan diskusi kelompok pada siswa kelas VI SD. Scholaria: Jurnal Pendidikan Dan Kebudayaan, 7(3), 283-291.

Kamaluddin, H. (2011). Bimbingan dan konseling sekolah. Jurnal Pendidikan

Dan Kebudayaan, 17(4), 447-454.

Kholis, N. (2000). Mencari Alternatif Formulasi Pengembangan Sistem Pendidikan Revolusioner Di Era Millenium Iii. NIZAMIA: Jurnal Pendidikan Dan Pemikiran Islam, 3, 1-10.

Kwartolo, Y. (2010). Teknologi informasi dan komunikasi dalam proses pembelajaran. Jurnal Pendidikan Penabur, 14, 15-43.

Nurillah, A. S., \& Muid, D. (2014). Pengaruh kompetensi sumber daya manusia, penerapan sistem akuntansi keuangan daerah (sakd), pemanfaatan teknologi informasi, dan sistem pengendalian intern terhadap kualitas laporan keuangan pemerintah daerah (studi empiris pada skpd kota depok). Fakultas Ekonomika dan Bisnis.

Pasaribu, H. E. R. (2005). Perbandingan Penyuluhan Kesehatan Metode Ceramah Tanya Jawab Dengan Penyuluhan Kesehatan Menggunakan Buku Kecacingan Dalam 


\section{W/AHANA DEDIKASI}

Mencegah Reinfeksi Ascaris lumbricoides Pada Anak Sekolah Dasar. Program Pascasarjana Universitas Diponegoro.

Pranoto, H., Wibowo, A., \& Atieka, N. (2017). Layanan Bimbingan Kelompok Mahasiswa Prodi BK Mengunakan Media ICT (Information AND Communications

Technology) Basis Social Media. MIKROTIK: Jurnal Manajemen Informatika, 7(2), 14-24.

Riwayadi, P. (2013). Pemanfaatan Perkembangan Teknologi Informasi Dan Komunikasi Untuk Kemajuan Pendidikan Di Indonesia. Available at PLS-UM Database.

Setyoningsih, Y. D. (2018). Tantangan Konselor di era milenial dalam mencegah degradasi moral remaja. In Prosiding Seminar Nasional Bimbingan dan Konseling (Vol. 2, pp. 134-145).

Sudarsana, I. K. (2018). Optimalisasi Penggunaan Teknologi Dalam Implementasi Kurikulum Di Sekolah (Persepektif Teori Konstruktivisme). Cetta: Jurnal Ilmu Pendidikan, 1(1),
$8-15$.

Sugiyanto, R. (2009). Penerapan Metode Bertanya dalam Kegiatan Praktek Lapangan untuk Meningkatkan Kemampuan Mengemukakan Pendapat Mahasiswa. Jurnal Geografi, 6(2).

Sumarwiyah, S., \& Zamroni, E. (2017). Pemanfaatan Tekonologi Informasi (TI) Dalam Layanan Bimbingan Dan Konseling Sebagai Representasi Berkembangnya Budaya Profesional Konselor Dalam Melayani Siswa. Jurnal Bimbingan Dan Konseling Ar-Rahman, 2(1).

Supriatna, M., \& Budiman, N. (2009). Bimbingan Karir di SMK. Dalam E-Book.

Supriyanto, W., \& Muhsin, A. (2008). Teknologi informasi perpustakaan. Kanisius.

Triyanto, A. (2010). Implikasi Perkembangan Teknologi Komputer dan Internet dalam Lapangan Konseling.

Triyono, T., \& Febriani, R. D. (2018). Pentingnya Pemanfaatan Teknologi Informasi Oleh Guru Bimbingan dan Konseling. JUANG: Jurnal Wahana Konseling, 1(2), 74-83. 